\title{
Influência do Treino em Habilidades Sociais na relação professor-aluno: uma contribuição psicopedagógica para professores ${ }^{1}$
}

\author{
Social Skills Training Influence on the \\ teacher-student relationship: \\ a psychopedagogical contribution for teachers
}

\author{
Dalva ALVES Silva \\ Maria AZNAR-FARIAS \\ Edwiges Ferreira de Mattos SILVARES
}

\section{RESUMO}

Neste estudo apresentamos os resultados do Treino em Habilidades Sociais para professores, utilizando o Módulo I do Programa de Educação Social e Afetiva (composto por três módulos), elaborado por Trianes e Muñoz (1994). O estudo teve por objetivos avaliar os efeitos desse treinamento na mudança de percepção dos professores a respeito dos alunos e deles sobre si mesmos, em relação às suas competências ou dificuldades comportamentais e emocionais. Para a coleta de dados foram utilizados os seguintes instrumentos: Teacher's Report Form (TRF) e Youth Self Report (YSR), ambos de Achenbach (1991). Os resultados apontaram efeitos positivos em relação ao treinamento, bem como a aproximação entre as percepções dos professores sobre os alunos e destes sobre si mesmos após a intervenção, além de mostrar a importância de a Escola abrir um espaço em sua programação para o ensino de habilidades sociais de relacionamento.

Palavras-chave: educação social e afetiva, problemas de comportamento; relação professor-aluno, treino em habilidades sociais.

\begin{abstract}
This article presents the results of the Social Skills Training (SST) dedicated to teachers using the first step (Module I) of the Social and Affective Educational Program (composed by three steps/ three modules course), elaborated by Trianes and Muñoz (1994). This study intents to evaluate the effects of the SST in the teacher's change of perception concerning the students and themselves, regarding their Skills, their behavior or mannering and emotional difficulties. To collect data information, the following
\end{abstract}

\footnotetext{
${ }^{1}$ Este artigo apresenta uma parte dos resultados obtidos na dissertação de mestrado da primeira autora, coorientado pela segunda e orientado pela terceira autora.
} 
instruments were used: Teacher's Report Form (TRF) and Youth Self Report (YSR), both elaborated by Achenbach (1991). The results indicates positive effects related to the training, the approach of the teachers perception concerning the students and themselves after the intervention, as well as demonstrates the importance of a school to introduce in its Study Program the Social and Relationship Skills teachings.

Index Terms: behavior problems, social and affection education, social skills training, teacher-student relationship.

\section{RÉSUMÉ}

Dans cette étude, nous présentons les résultats d' "Entraînement des Habiletés Sociales" pour les enseignants, en utilisant le Module I du "Programme d'Éducation Sociale et Affective" (composé de trois modules), établi par Trianes et Muñoz (1994). L'étude a eu pour objectif d'évaluer les effets du changement de la perception des enseignants concernant ses élèves et le respect sur eux-mêmes, par rapport à leurs compétences ou leurs difficultés de comportement et réactions émotionnelles. Pour le recueil des données les instruments suivants ont été utilisés: Teacher's Report Form (TRF) e Youth Self Report (YSR), tous deux de Achenbach (1991). Les résultats ont démontré les effets positifs de la formation, ainsi que le rapprochement entre les perceptions des enseignants par rapport aux élèves et les perceptions des élèves par rapport à eux mêmes après l'intervention. Tout cela démontre l'importance d'avoir l'enseignement de ces compétences dans les écoles.

Mots clés: éducation sociale et "affective", formation des compétences sociales; problèmes de comportement, relation étudiants enseignants.

\section{Introdução}

Ainda que os obstáculos sejam muitos, a Psicopedagogia se constrói incessantemente, como que voltando para si aquilo a que se propõe: auxiliar o ser humano a superar-se nas adversidades por meio da aprendizagem.

(Nádia Bossa)

Em estudos desenvolvidos especialmente na última década, pesquisadores estão defendendo a idéia do quão importante é incluir o ensino de habilidades sociais em programas escolares desde os anos inicias de escolaridade e, sobretudo, nos cursos de capacitação e aperfeiçoamento para pro- 
fessores (TRIANES; MUÑOZ; 1994, JIMÉNEZ, 1997; TRIANES, DE LA MORENA; MUÑOZ, 1999; DEL PRETTE; DEL PRETTE, GARCIA et al, 1998; DEL PRETTE; DEL PRETTE, 2003; MELO, 2004, VILA, 2005).

Zagury (2006) apresentou os resultados de seu estudo abrangendo professores do Ensino Básico (Ensino Fundamental e Médio), de escolas particulares e públicas, de 42 cidades, em 22 estados do país, cujo objetivo foi obter uma amostra representativa do pensamento do professor brasileiro. Os resultados mostraram que manter a disciplina e motivar os alunos foram as queixas mais representativas das dificuldades do professor, apontadas por $43 \%$ deles, de todas as regiões do país, nos dois níveis de ensino (Fundamental e Médio), tanto da rede privada como da particular.

De fato, os professores têm encontrado dificuldades e sentido a necessidade de orientação para lidar com questões de disciplina e comportamentos inadequados na sala de aula (BORGES; MATURANO, 2003). Estes contribuem para a desordem no ambiente da sala de aula e criam um clima desfavorável para a aprendizagem. Gotzens (2003) diz que a questão da falta de disciplina escolar tem sido motivo de inquietação e alarme por parte de professores e pais em diferentes países do mundo ocidental; e considera que a disciplina (um conjunto de procedimentos, normas e regras - não repressor) tem um caráter funcional e instrumental que favorece certo nível de ordem entre os alunos para que o processo de ensino e de aprendizagem possa se desenvolver. Para a pesquisadora, a disciplina é importante, necessária e parte de um conjunto de habilidades que compõe a competência social e deveria estar entre os temas trabalhados na escola.

Falcone (2000) reforça a tese de que comportamento social e valores podem ser aprendidos, primeiro, com os pais, e posteriormente, com a escola. Dessa forma, torna-se necessário o preparo para lidar com uma educação "mais integral, não voltada apenas para o ensino dos conteúdos acadêmicos" (HARGREAVES; EARL; RYAN, 2001), mas também voltada à construção de um repertório socialmente habilidoso (GOTZENS, 2003). 
De acordo com Trianes, De La Morena e Muñoz (1999, p. 12) e Aznar-Farias (2000) a instituição escolar não é única responsável pela educação de crianças e jovens, contudo, nas sociedades urbanas as crianças estão ingressando na escola cada vez mais cedo, nela permanecendo por várias horas do dia e por um longo período de suas vidas. Com essa transformação sócio-cultural cada vez mais crescente, a escola passa a abranger também o papel familiar de educação das crianças desde os anos iniciais de seu desenvolvimento e ao longo de sua formação.

Vila (2005, p. 94), realizou um treinamento de habilidades sociais em um grupo de professores de crianças com dificuldade de aprendizagem e pensa que "o trabalho desenvolvido realçou a evidência da importância do aprimoramento do repertório de habilidades sociais do professor para a prevenção e/ou superação das dificuldades acadêmicas e para o desenvolvimento interpessoal dos alunos". Este resultado reforça, juntamente com os trabalhos de Trianes e Muñoz (1994), Jiménez (1997), Trianes et al (1999), Del Prette e Del Prette (2001, 2003), a idéia de que o professor encontra no ambiente escolar um campo fértil, não só para o ensino de habilidades acadêmicas, mas também um espaço de interação social que possibilita levar o aluno a crescer, respeitar-se e a respeitar os outros.

Conhecer os alunos, perceber seus talentos, dificuldades, necessidades, ou ainda sinais de problemas que possam estar afetando seu desempenho escolar e de relacionamentos, são tarefas importantes a serem realizadas pelos professores, de todos os níveis de ensino, inclusive, por professores que trabalham com alfabetização de crianças, jovens e adultos ou estudantes universitários. Trianes e Muñoz (1994) afirmam que o professor que conhece seus alunos ajuda-os na prevenção de problemas de adaptação escolar e têm melhores condições de promover situações que favoreçam o ensino e a aprendizagem. Ademais, quando o professor conhece seus alunos, pode evitar que encaminhamentos indevidos aconteçam e auxiliar que crianças e adolescentes com problemas reais, escolares ou de outra ordem, possam ser 
atendidos de acordo com suas necessidades (MASSOLA; SILVARES, 1997).

Uma análise da produção nacional a respeito da aplicação do Treino em Habilidades Sociais para a prevenção primária, secundária e terciária foi realizada por Murta (2005). Seu estudo abrangeu trabalhos publicados nas últimas décadas e identificou, dentre as publicações nacionais, 17 programas de intervenção. De acordo com a pesquisadora, embora esse número seja relativamente pequeno se comparado à quantidade de programas desenvolvidos no exterior - um total de 342 estudos encontrados a partir de sua pesquisa em uma base de dados eletrônica - é notável o crescimento desse tipo de programa de treinamento em nosso país.

Dentro de uma abordagem psicopedagógica, voltada para a intervenção em grupo no contexto escolar, Trianes e Muñoz (1994) desenvolveram um programa de educação - que utilizamos em nosso estudo com professores - abrangendo um conjunto de atividades voltadas para a aprendizagem de habilidades sociais de relacionamento, em que o professor tem um papel fundamental. O programa compreende três módulos (Módulos I, II e III) e pretende criar um ambiente de confiança, trabalho cooperativo e autogestão. Está voltado para o ensino e promoção de habilidades de negociação, solução de problemas, assertividade, empatia, inclusão social e escolar e comportamento em sala de aula.

Trianes e Muñoz (1994) justificam que o programa foi desenvolvido em seu conjunto (três módulos), para atender a três principais vias de aplicação. Uma relativa à promoção do desenvolvimento global do aluno, trabalhando as relações sociais e afetivas, buscando o enriquecimento e a felicidade do aluno como indivíduo em formação; outra, relativa à prevenção de problemas de adaptação e rendimento escolar, especialmente, relacionados à falta de habilidades e competência social dos alunos, e uma terceira, relativa à instrumentalização do professor para o manejo e a resolução de problemas na classe, tais como: a existência de alunos à margem do ritmo da classe; 
grupos de características étnicas ou sócio-culturais diferentes e de difícil integração; comportamento de determinados alunos que repercutem no ritmo da classe; relações agressivas, brigas e ambiente tenso ou, ainda, quando há alunos tímidos e inseguros.

Em nosso estudo tivemos como objetivo avaliar a influência do Treino de Habilidades Sociais na relação professor/aluno e comparar a percepção dos professores a respeito de seus alunos e desses a respeito de si mesmos; mediante a comparação dos dados fornecidos pelo inventário de rastreamento de comportamentos para professores (Teacher's Report Form [TRF]), e pelo inventário de comportamentos para alunos (Yulth Self Report [YSR]), ambos de Achenbach (1991), aplicados antes e após o treinamento dos professores.

\section{Método}

Realizamos um estudo empírico que contou com a participação de 8 professores (escolhidos por sorteio dentre os 11 que inicialmente se dispuseram a participar) e seus cento e treze (113) alunos do segundo ciclo do Ensino Fundamental ( $5^{\mathrm{a}}$ a $8^{\mathrm{a}}$ série), de uma escola pública estadual, localizada na capital de São Paulo. A participação dos alunos se deu por meio do preenchimento do inventário de comportamento (YSR). Os professores foram distribuídos em 2 grupos de 4 participantes: um Grupo de Treinamento ( $\mathrm{n}=$ 4 prof.) e um Grupo Controle ( $n=4$ prof.).

Para a coleta de dados utilizamos os seguintes instrumentos: TRF e YSR, ambos de Achenbach (1991). Estes inventários de rastreamento de comportamentos apresentam afirmações de fácil compreensão como, por exemplo: é desobediente na escola; mostra-se apático ou desmotivado; chega atrasado às aulas, entre outras. Estas afirmações devem ser assinaladas em termos de freqüência, pelos respondentes, circulado zero (0) para nunca, um (1) para algumas vezes e dois (2) para muitas vezes. As respostas sinalizadas permitem que sejam discriminados os comportamentos internalizan- 
tes, externalizantes e de funcionamento global dentro de um status clínico e não-clínico, determinado pelo escore de corte acima de 60 pontos. Os comportamentos internalizantes (DI) são aqueles que correspondem aos comportamentos introspectivos como, por exemplo, isolamento, perder-se em seus próprios pensamentos, timidez, tristeza etc. Os externalizantes (DE) correspondem aos comportamentos diretamente observáveis e explícitos como discutir com colegas ou agredi-los fisicamente ou com palavras; gritar, destruir suas próprias coisas ou as de alguém, entre outros. Os comportamentos discriminados como funcionamento global (DT) incluem os internalizantes, os externalizantes e os comportamentos que aparecem sob a denominação "outros problemas". Os dois instrumentos (TRF e YSR) oferecem informações relevantes sobre o conhecimento que o professor tem de seu aluno e do aluno sobre si mesmo. Utilizamos em nosso estudo a segunda parte dos dois inventários, composta das questões de 1 a 113, que dão um perfil do aluno em relação a suas dificuldades comportamentais e emocionais.

Para o Treino em Habilidades Sociais com os professores utilizamos o primeiro módulo do Programa de Educação Social e Afetiva, de Trianes e Muñoz (1994). Esse módulo compreende um conjunto de 17 atividades voltadas para o relacionamento professor/alunos, por exemplo, atividade 1: apresentação pessoal e declaração de duas coisas que mais gosta; atividade 4: formar grupos por preferências e gostos; atividade 6: diferentes grupos de pertencimento; atividade 7: questões de inclusão: resolvendo um problema; atividade 9: sobre diferenças individuais; atividade 12: levantamento dos problemas da classe; atividade 15: funcionamento da classe: responsabilidade individual e grupal. O conjunto de atividades pode ser aplicado no treinamento de professores de diferentes níveis de ensino, feitas as adequações necessárias à idade/série dos alunos.

O estudo foi desenvolvido em seis etapas, da seguinte forma: na primeira realizamos contatos com a direção da escola para a autorização do 
treinamento e convite aos professores; na segunda, após o aceite, fizemos um sorteio e distribuímos os oito professores em dois grupos: o grupo de treinamento $(\mathrm{GT})$ - que recebeu orientações teóricas e práticas - e o de controle (GC) - que não recebeu treinamento nem orientações. O GT foi composto por um professor e três professoras, todos de Língua Portuguesa ( $5^{\mathrm{a}}$ a $8^{\mathrm{a}}$ séries). O GC foi composto por uma professora de Geografia (5 série), um professor de História ( $6^{\mathrm{a}}$ série) e duas professoras de Matemática ( $7^{\mathrm{a}}$ e $8^{\mathrm{a}}$ séries). Na terceira etapa realizamos a coleta de dados préintervenção; para essa finalidade os professores dos dois grupos receberam as cópias do inventário TRF e tiveram um período de 40 dias para preenchêlas. Simultaneamente, os alunos responderam o inventário YSR, durante o período de uma aula cedida pelos professores do grupo de treinamento, ocasião em que lhes foi explicado o trabalho que seria desenvolvido com seus professores. Na quarta etapa realizamos o treinamento dos professores no Horário de Trabalho Pedagógico Coletivo (HTPC), em uma das salas de aula desocupadas, num total de 19 encontros. Em cada um deles foi feita a leitura das atividades, instrução verbal, ensaio de prática, feedback sobre a atuação e esclarecimento de dúvidas. Na quinta etapa realizamos a coleta de dados pós-intervenção, quando professores de ambos os grupos (GT e GC) preencheram os TRF e seus alunos o YSR. Além disso, os professores do GT responderam ao Guia de Observação de Efeitos da Aplicação do módulo — um guia de observação para auxiliar o professor na avaliação de mudanças ocorridas com a aplicação das atividades. Finalmente, na sexta etapa, analisamos os dados dos inventários que foram digitados no programa desenvolvido para este fim por Achenbach ${ }^{2}$.

\section{Resultados}

\footnotetext{
${ }^{2}$ Disponível em: <www.aseba.com>.
} 
Na Tabela 1, a seguir, apresentamos a distribuição detalhada dos dados coletados nos inventários TRF e YSR. É possível observar a perda de participantes do GC, isto porque a professora da $5^{\mathrm{a}}$ série foi transferida para outra escola onde se tornou coordenadora e o professor da $6^{\mathrm{a}}$ série tirou licença-prêmio. Dessa forma, apenas o GT permaneceu com sua constituição inicial (um professor e três professoras) e o GC ficou composto apenas por duas professoras. A diminuição da quantidade de YSR respondidos -113 para 101 (depois do treinamento) - deveu-se às faltas dos alunos no dia da segunda aplicação do YSR. O aumento de TRF respondidos pela professora da $7^{\mathrm{a}}$ série do GC na coleta de dados após a intervenção (25, antes; 38 , depois), deveu-se ao seu interesse pelo treinamento.

Tabela 1 - Participantes e número de inventários por eles respondidos nos dois momentos - antes e depois do treinamento dos professores

\begin{tabular}{|c|c|c|c|c|c|}
\hline & \multicolumn{5}{|c|}{ RESPOSTAS AOS INVENTÁRIOS } \\
\hline & $5^{\text {a }}$. série & $6^{\text {a }}$. série & $7^{\text {a }}$. série & $8^{\text {a }}$. série & TOTAL \\
\hline ANTES DO TREINAMENTO & & & & & \\
\hline YSR - alunos & 32 & 15 & 37 & 29 & 113 \\
\hline TRF - Professores do GT & 39 & 25 & 40 & 35 & 139 \\
\hline TRF - Professores do GC & 0 & 8 & 25 & 36 & 69 \\
\hline DEPOIS DO TREINAMENTO & $\mathbf{7 1}$ & $\mathbf{4 8}$ & $\mathbf{1 0 2}$ & $\mathbf{1 0 0}$ & $\mathbf{3 2 1}$ \\
\hline YSR - alunos & 29 & 12 & 31 & 29 & 101 \\
\hline TRF - Professores do GT & 34 & 12 & 29 & 33 & 118 \\
\hline TRF - Professores do GC & 0 & 0 & 38 & 33 & 71 \\
\hline & $\mathbf{6 3}$ & $\mathbf{2 4}$ & $\mathbf{1 0 8}$ & $\mathbf{9 5}$ & $\mathbf{2 9 0}$ \\
\hline & \multicolumn{6}{|c|}{ Total geral dos inventários analisados } & $\mathbf{5 1 1}$ \\
\hline
\end{tabular}

O Guia de Observação dos efeitos da aplicação do treinamento, apresentado no Quadro 1, forneceu-nos a avaliação dos professores quanto ao treinamento. Para essa análise consideramos a freqüência das respostas SIM e NÃO da folha de avaliação.

Quadro 1. Resultado da avaliação dos Professores sobre as mudanças no clima da classe, decorrentes da aplicação do Módulo I 


\begin{tabular}{|c|c|c|c|c|c|}
\hline \multicolumn{6}{|c|}{ GUIA DE OBSERVAÇÃO DE EFEITOS DA APLICAÇÃO DO MÓDULO I } \\
\hline \multirow{2}{*}{ Afirmações } & \multicolumn{4}{|c|}{ Resultados } & \multirow{2}{*}{$\begin{array}{c}\text { Geral } \\
(\% \text { de } \operatorname{sim})\end{array}$} \\
\hline & $5^{a_{s}}$ & $6^{\mathrm{a}} \mathrm{s}$ & $7^{a_{s}}$ & $8^{\mathrm{a}} \mathrm{s}$ & \\
\hline $\begin{array}{l}\text { 1. Os alunos parecem mais desinibidos para } \\
\text { se comunicarem e falarem de si mesmos }\end{array}$ & Sim & Sim & Sim & Sim & $100 \%$ \\
\hline $\begin{array}{l}\text { 2. Interagem mais entre si, parecem relevar } \\
\text { os grupinhos e as preferências excludentes }\end{array}$ & Sim & Sim & Sim & Sim & $100 \%$ \\
\hline $\begin{array}{l}\text { 3. Têm-se mostrado bastante objetivos na } \\
\text { análise dos problemas da aula e suas } \\
\text { conseqüências }\end{array}$ & Sim & Sim & Sim & Sim & $100 \%$ \\
\hline $\begin{array}{l}\text { 4. Participam ativamente nos debates e } \\
\text { discussões dos grupos, tanto nos de trabalho } \\
\text { como nos debates gerais da classe }\end{array}$ & Sim & Sim & Sim & Não & $75 \%$ \\
\hline \begin{tabular}{|l|} 
5. Verbalizam em ocasiões os valores e \\
termos que trabalha o modulo: "sentir-se bem \\
ou mal em conseqüência de uma conduta \\
própria ou de outro... respeito pelos direitos e \\
características diferenciais dos demais... \\
responsabilidade no andamento da classe..." \\
\end{tabular} & Sim & Sim & Sim & Sim & $100 \%$ \\
\hline $\begin{array}{l}\text { 6. Participam ativamente na avaliação dos } \\
\text { comportamentos em relação às normas } \\
\text { propostas (podem não ser muito objetivos, se } \\
\text { são pequenos, devendo o professor mudar } \\
\text { esta tendência) }\end{array}$ & $\mathrm{Sim}$ & Sim & Sim & Não & $75 \%$ \\
\hline $\begin{array}{l}\text { 7. Começam a relevar os } \\
\text { comportamentos-problema, sobre todos os } \\
\text { disruptivos ou agressivos }\end{array}$ & Não & Sim & Sim & Sim & $75 \%$ \\
\hline $\begin{array}{l}\text { 8. Começa a integração dos alunos margina- } \\
\text { lizados, que vão participando nas atividades } \\
\text { mesmo com ritmo mais lento que os demais }\end{array}$ & $\operatorname{Sim}$ & Sim & Sim & Não & $75 \%$ \\
\hline \begin{tabular}{|l|} 
9. Começa haver interação ou certa aceitação \\
desses alunos marginalizados por parte dos \\
demais, no meio das atividades da classe
\end{tabular} & Sim & Sim & Sim & Sim & $100 \%$ \\
\hline
\end{tabular}

As freqüências das respostas positivas (SIM) a esta avaliação variaram entre $75 \%$ e $100 \%$, indicando que a avaliação dos professores em relação aos efeitos do treinamento foi positiva.

No tratamento estatístico referente aos dados obtidos nos TRF e YSR foram consideradas as variáveis sexo e série dos alunos nas escalas DI (Distúrbio Internalizante), DE (Distúrbio Externalizante) e DT (Distúrbio Total), nas faixas Clínica e Não-clínica com base no escore de corte acima de 60 pontos. Foram realizados o Teste ANOVA, o Teste Fisher e o Teste de Kappa, considerando um intervalo de confiança de $95 \%$ em todos os testes. Estes resultados são apresentados a seguir. 
Em relação à variável sexo dos alunos, na Figura 1 é possível verificar que, embora as médias dos escores encontrem-se na faixa Não-clínica, os professores percebem mais os meninos com problemas de comportamento em todas as escalas. Contudo, tanto a ANOVA $(\mathrm{p}>0,05)$ como o Teste exato de Fisher ( $p>0,05)$, na comparação entre os sexos de acordo com a percepção dos professores, não apresentou significância para as médias nas escalas, indicando que os problemas de comportamento não estavam associados a essa variável.

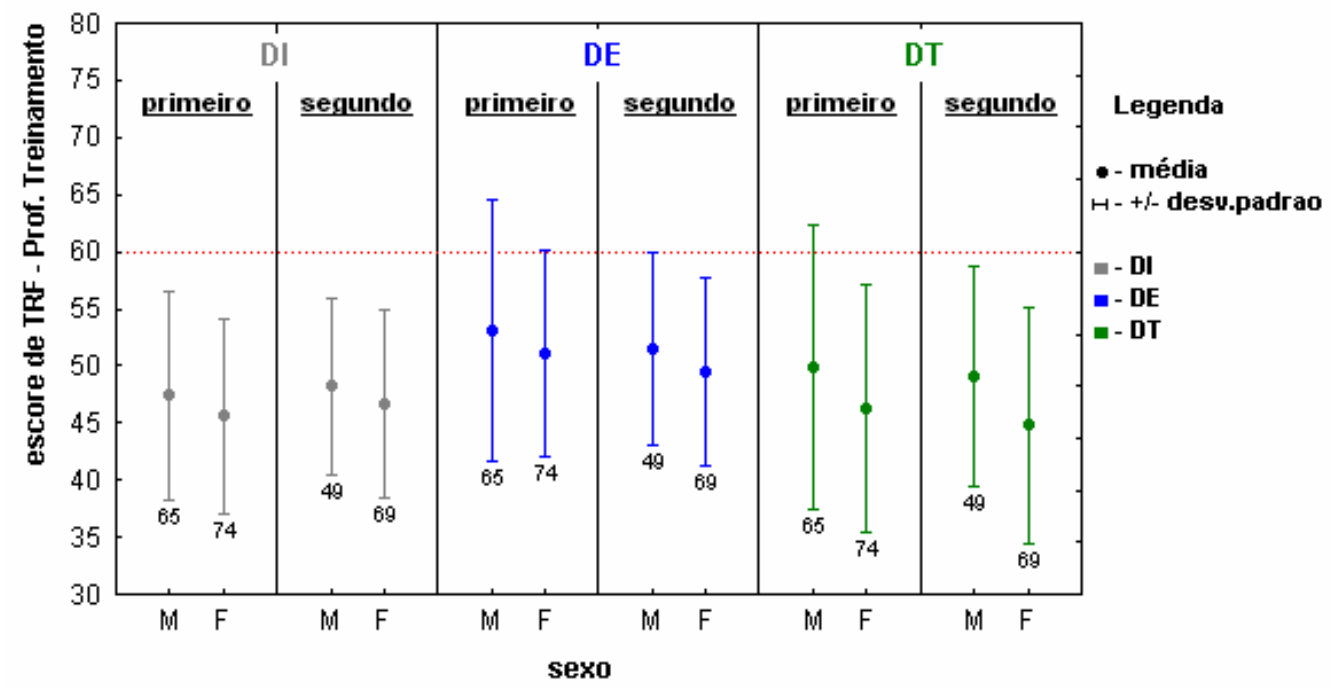

Figura 1 - Distribuição das Médias e Desvio-padrão, por sexo dos alunos, nas escalas DI, DE e DT, de acordo com a percepção dos professores do GT, antes do treinamento (primeiro) e depois do treinamento (segundo).

A Figura 2 apresenta a percepção dos alunos sobre si mesmos em relação à variável sexo. É possível notar que os alunos se percebem de forma diferente de como os professores os percebem. Nota-se que as meninas se perceberam significativamente pior que os meninos na escala DE. Para esta escala, o Teste de Fisher apontou nível de significância $\mathrm{p} \leq 0,033 \mathrm{e}$ 0,002 , antes e depois do treinamento respectivamente. O Teste de médias (ANOVA), mostrou um $p=0,016$, antes, e $p=0,000$, depois do treinamento. Estes últimos resultados se refletiram em DT, no segundo momento, com um nível de significância de $\mathrm{p}=0,034$. 


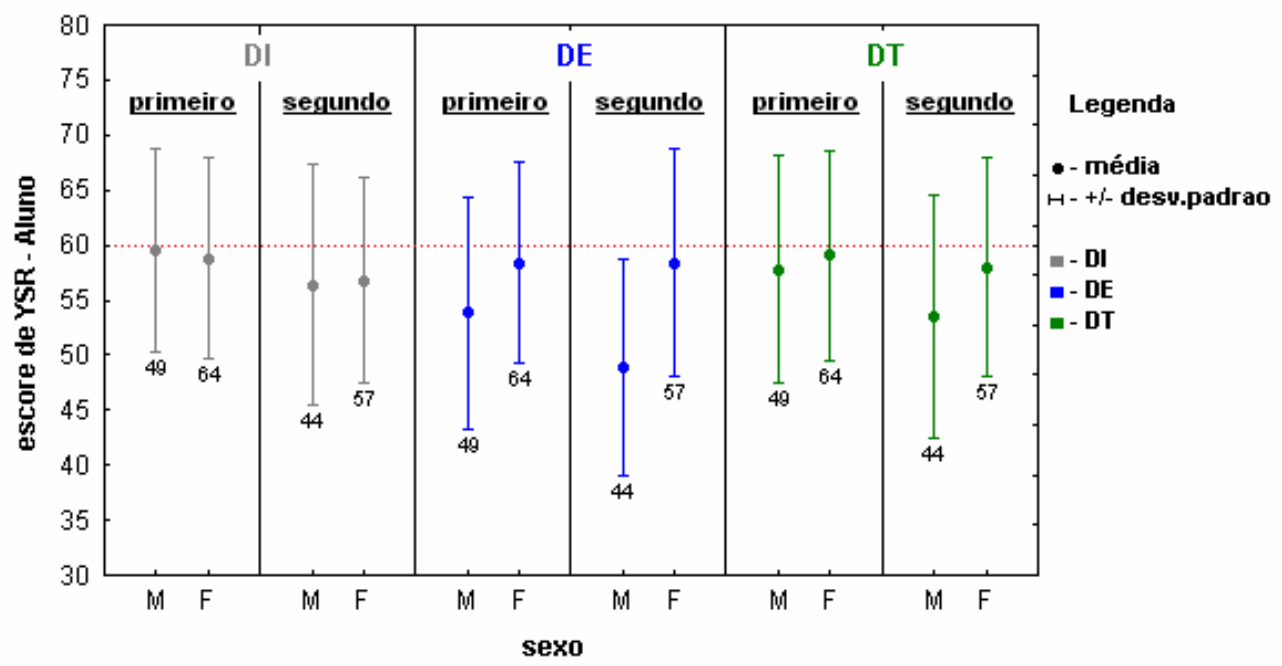

Figura 2 - Distribuição das Médias e Desvio-padrão, por sexo, nas escalas DI, DE e DT, de acordo com a percepção dos alunos sobre si mesmos, antes do treinamento (primeiro) e depois do treinamento (segundo).

A Figura 3 apresenta os resultados da percepção dos professores em relação à variável série. É possível observar que as médias estão abaixo do escore de corte (60 pontos) para a faixa Clínica em todas as escalas, antes e após o treinamento, o que significa que os professores viram seus alunos na faixa Não-clínica em ambos os momentos, isto é, não apresentando problemas importantes de comportamento. No segundo momento, na escala DT, observa-se que o desvio-padrão diminuiu para todas as séries, destacando-se a não variação das respostas dadas pela professora da $8^{\mathrm{a}}$ série, que respondeu a todos os inventários assinalando a mesma coluna de respostas, o que resultou em escores de 33 e 35 pontos para todos os alunos. 


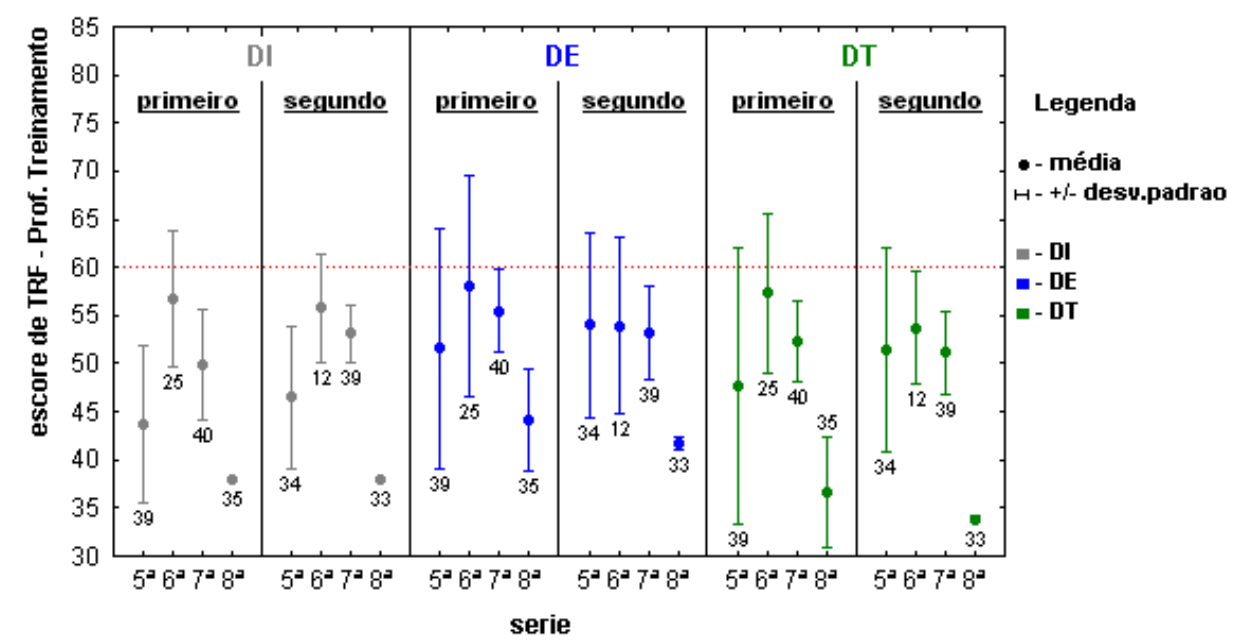

Figura 3 - Distribuição das Médias e Desvio-padrão, por série, nas escalas DI, DE e DT, de acordo com a percepção dos professores, antes do treinamento (primeiro) e depois do treinamento (segundo).

Diferentemente da percepção dos professores, ao se observar a Figura 4 é possível notar que as médias do YSR, de um modo geral, mostram que os alunos se vêem pior do que os professores os vêem, especialmente na escala DI. Podemos destacar, ainda, que a $5^{\mathrm{a}}$ série foi a única, antes da intervenção, a se encontrar na faixa Clínica na escala DI. Após o treinamento o escore médio obteve leve redução, situando esta turma na linha de corte (60 pontos). Contudo, ao contrário da $5^{\mathrm{a}}$ série, o escore médio da $8^{\mathrm{a}}$ série, que inicialmente encontrava-se na faixa Não-clínica na escala DE, na segunda avaliação passou para a linha de corte adentrando levemente na faixa Clínica na mesma escala. A $7^{\mathrm{a}}$ série passou a se ver de forma mais positiva, ao contrário da $6^{\mathrm{a}}$ série que passou a se ver em média com mais problemas de comportamento. Na escala DT, após a intervenção, é possível observar que a visão dos alunos, por série, mostrou-se mais positiva, situando todas as séries abaixo da linha de corte. Eles passaram a se perceber significativamente diferentes em todas as escalas, cujos testes apontaram um nível de $\mathrm{p} \leq 0,017$ para a ANOVA, indicando que as médias das séries não eram iguais entre si. O Teste de Fisher apresentou um nível de $\mathrm{p} \leq 0,009$, nas escalas DI e DT, indicando que os alunos tinham percepções diferentes sobre 
si mesmos dependendo da série em que estavam, ou seja, encontramos excesso de alunos na faixa Clínica, na $5^{\mathrm{a}}$ série, na escala DI e nenhum na mesma posição, na $7^{\mathrm{a}}$ série, na mesma escala, por exemplo.

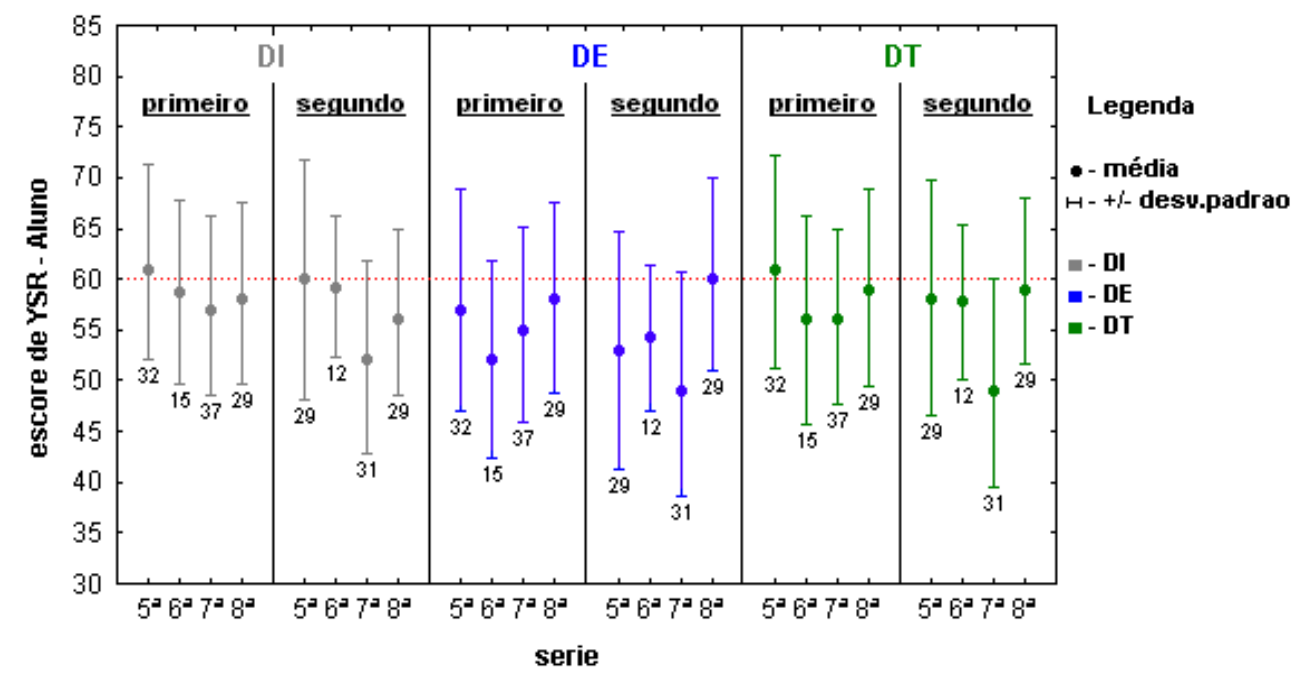

Figura 4 - Distribuição das Médias e Desvio-padrão, por série, nas escalas DI, DE e DT, de acordo com a percepção dos alunos, antes do treinamento (primeiro) e depois do treinamento (segundo).

Na Tabela 2, é possível observar pelo Teste de Kappa, que as freqüências de concordâncias nas três escalas tanto antes como depois, estão longe de serem consideradas ideais. Contudo mudanças positivas ocorreram e a evolução pode ser observada no momento depois do treinamento quando a discordância entre TRF e YSR diminuiu nas três escalas: DI, DE e DT.

Tabela 2 - Concordância e discordância entre TRF/YSR em relação às escalas DI, DE e DT, antes e depois do treinamento dos professores

\begin{tabular}{|c|c|c|c|}
\hline Variável estatística & \% de concordância & \% de discordância & coef. de Kappa $^{\mathbf{S}}$ \\
\hline Antes - Grupo Treinamento x alunos & & & \\
\hline número de respostas = 112 & & & \\
\hline DI & $47,3 \%$ & $52,7 \%$ & 0,070 \\
\hline DE & $58,0 \%$ & $42,0 \%$ & 0,062 \\
\hline DT & $53,6 \%$ & $46,4 \%$ & 0,070 \\
\hline Depois - Grupo Treinamento x alunos & & & \\
\hline número de respostas = 98 & & & 0,029 \\
\hline DI & $63,3 \%$ & $36,7 \%$ & 0,059 \\
\hline DE & $63,2 \%$ & $36,8 \%$ & 0,030 \\
\hline DT & $59,2 \%$ & $40,8 \%$ & \\
\hline
\end{tabular}

\footnotetext{
${ }^{3}$ Coef. de Kappa = medida de concordância entre 0 e 1, sendo 1 a total concordância.
} 
A seguir, os resultados encontrados no Teste de duas proporções independentes, apresentados na Tabela 3, indicam que houve diferença significante de aumento da concordância do primeiro momento para o segundo, na escala DI $(\mathrm{p}=0,042)$. Nas demais escalas, embora não se observe significância estatística ( $p>0,050)$ é possível notar que as mudanças ocorreram em ambas as escalas (DE e DT).

Tabela 3 - Comparação da freqüência de concordância entre professores antes e depois do treinamento $\left(1^{\circ}\right.$. e $2^{\circ}$. momentos)

\begin{tabular}{|c|c|c|c|}
\hline \multirow{2}{*}{ Variável } & \multicolumn{2}{|c|}{ Porcentagem de concordância } & $\begin{array}{c}\text { Comparação entre o antes } \\
\text { e o depois do treinamento* }\end{array}$ \\
\cline { 2 - 3 } & $\mathbf{1}^{\mathbf{0}}$. momento & $\mathbf{2}^{\mathbf{o}}$. momento & Valor - p \\
\hline Prof. treinamento - aluno & & & $0,042^{*}$ \\
\hline DI & $47,3 \%$ & $63,3 \%$ & 0,274 \\
\hline DE & $58,0 \%$ & $63,2 \%$ & 0,269 \\
\hline DT & $53,6 \%$ & $59,2 \%$ & \\
\hline
\end{tabular}

*Teste de duas proporções independentes $\mathrm{p} \leq 0,050$.

\section{Discussão}

Para os professores que participaram da nossa pesquisa, a falta de compromisso dos alunos e seus problemas de comportamento são dificuldades que encontram no dia-a-dia e não sabem como resolvê-las. "Os jovens de hoje - diziam-nos - conquistaram a possibilidade da livre expressão de suas idéias, pensam e falam o que querem, fazem suas reivindicações, e consideramos isso muito bom, porém, muitas vezes, não o fazem com o devido respeito ao outro, especialmente, a nós, professores. Sentimo-nos desmotivados e sem saber como trabalhar com os alunos, acreditamos que há muita proteção para os alunos e poucos recursos para nós, professores”.

No entanto, ao responderem o inventário de rastreamento de comportamentos (TRF), não assinalaram as afirmações indicativas de comportamentos problemáticos dos alunos, mostrando uma distância entre suas queixas orais e as registradas nos inventários. Contudo, a nosso ver suas palavras precisavam ser ouvidas.

Reconhecemos que não é mesmo fácil manter-se animado durante uma longa jornada de trabalho diário, muitas vezes indo de uma escola para 
outra, sem valorização, reconhecimento e, ainda, enfrentando situações de humilhação. Certa vez, presenciamos, quando de uma visita que fizemos à escola para a coleta de dados, ao participar por alguns instantes de uma aula, em uma $8^{\mathrm{a}}$ série, um dos alunos dirigir algumas palavras à professora, que escrevia na lousa: "tira o cabeção daî". Em nosso entender - e pensamos que também no entender da professora - a expressão desrespeitosa usada pelo aluno significava: “com licença, professora, pois não consigo enxergar o que está escrito no quadro". No entanto, o barulho geral da classe era tanto, que a professora continuou escrevendo e nenhum comentário fez, ou qualquer outra atitude tomou.

Colocamo-nos a pensar como era possível um clima daqueles favorecer uma aprendizagem de qualidade e mesmo a preparação para a vida?! Não há dúvida que, no momento atual, os professores precisam ser ouvidos em suas queixas e orientados em suas práticas. Concordamos com Zagury (2006, p. 85) quando diz que, se antes os professores davam conta das questões comportamentais em sala de aula, atualmente, não é mais assim, pois a situação beira o "fora de controle". Este tipo de comunicação entre aluno e professor está cada vez mais freqüente, o que a nosso ver indica a necessidade de estudos que promovam não só o trabalho com o professor, mas que envolvam membros da equipe escolar como um todo.

No que se refere à distância entre as queixas verbais, apresentadas espontaneamente pelos professores durante o treinamento, e o seu registro escrito no TRF, levantamos duas hipóteses para este dado. A primeira referente à falta de hábito de registro de ocorrências positivas e negativas no dia-a-dia de suas aulas. Castro (2004) considera importante o registro escrito, pois ele ordena o "caos" aparente dos diversos acontecimentos na sala de aula que interferem nas atividades pedagógicas. Freqüentemente a emoção que envolve uma determinada situação leva a deturpar o fato ocorrido, outras vezes leva ao exagero de sua descrição, outras, ainda, faz com que se rotule indevidamente um determinado aluno. A segunda hipótese refere-se 
ao fato do TRF ser um instrumento objetivo de observação do aluno que apresenta uma listagem detalhada de comportamentos. Isto propicia que o professor, ao preenchê-lo, pense sobre cada aluno e reflita sobre as queixas que faz.

As respostas dos professores ao Guia de Observação dos Efeitos da aplicação das atividades do treinamento apontaram resultados favoráveis a um movimento positivo no relacionamento entre professores e alunos no ambiente de sala de aula.

Trianes e Muñoz (1994) consideram que as mudanças proporcionadas pela aplicação das atividades do módulo acontecem em dois níveis. Um relativo à construção de valores, possível quando os alunos criam atitudes e crenças que os levam a mostrar novos padrões de ação em situações determinadas. Outro, relativo à organização, pois conforme os alunos vão internalizando novos valores vão se deparando com situações em que muitos valores são exigidos. Vários deles tornam-se relevantes, o que os leva à necessidade de pensar e agir de forma mais organizada e relacionada com o contexto. Estas mudanças são possíveis, no entanto, quando os alunos passam a se conhecer melhor e a expressar-se de forma mais livre e com mais rigor de pensamento.

Assim, pudemos observar, por exemplo, que alguns comportamentos assinalados pelos professores no Guia de Observação, indicavam que estava sendo estabelecido um clima harmonioso e de confiança entre os alunos e o professor. Por exemplo, falar de si mesmo requer que os alunos sintam-se acolhidos e ouvidos pelo grupo e pelo professor. Para isso é preciso que haja confiança entre eles.

De acordo com o professor da $5^{\mathrm{a}}$ série, seus alunos ainda não estavam propensos a relevar os comportamentos inadequados de alguns colegas. Hargreaves et al (2001) colocam que os adolescentes, ao ingressarem na $5^{\text {a }}$ série, sofrem uma mudança de status que pode influenciar em seu desempenho acadêmico e social. Eles egressam do nível superior de um ciclo educa- 
cional ( $4^{\mathrm{a}}$ série), onde eram os mais velhos, para o nível inferior do novo ciclo ( $5^{\mathrm{a}}$ série), onde são os menores, os mais jovens, o que representa uma diminuição de status. Além da modificação no status, há toda uma modificação da cultura escolar (vários professores, diminuição da atenção individualizada, menos flexibilidade nos horários das disciplinas, novo ciclo social, entre outras).

Já os alunos da $8^{\mathrm{a}}$ série sofrem o impacto da previsão das mudanças que ocorrerão em decorrência da mudança de nível de escolaridade no ano seguinte. Nesta fase, muitos estão envolvidos com a necessidade de trabalho, com a perspectiva de freqüentarem o período noturno, além dos mitos assustadores passados por professores e por alunos de séries mais avançadas sobre as dificuldades que encontrarão. Contudo, no decorrer das vivências escolares do novo ciclo, os alunos descobrem que este é melhor do que esperavam. Inclusive mais interessante e menos difícil. E isto se reflete na percepção de si mesmos e em sua auto-estima.

Em ralação aos inventários TRF e YSR, apesar de as médias das escalas estarem abaixo da linha de corte (60 pontos), as escalas DE e DT foram aquelas em que encontramos maior número de alunos considerados na faixa Clínica pelos professores nos dois momentos. Acreditamos que isto se deveu ao fato de os comportamentos que estão agrupados na escala de externalização (DE) serem mais fáceis de se observar como, por exemplo, gritar muito, perturbar os colegas, falar demais, falar palavrões.

A exceção foi percebida nos TRF da $6^{\mathrm{a}}$ série, cujos resultados dos TRF indicaram excesso de alunos com escores na faixa Clínica em todas as escalas, especialmente na escala DI. A literatura aponta que as dificuldades de aprendizagem e os problemas de comportamento muitas vezes estão associados prejudicando a aprendizagem e a socialização e, na maioria dos casos, torna-se difícil apontar qual é causa e qual é conseqüência (DEL PRETTE; DEL PRETTE, 2001; JAMES; JAVALOYES, 2001; BOLSONISILVA; MARTURANO, 2002; ZAGURY, 2006). 
Quanto à $8^{\mathrm{a}}$ série, de acordo com a professora, não foi possível incluir as atividades na programação como pretendia, pois precisava terminar os conteúdos. Hargreaves et al (2001) consideram uma visão estreita a orientação predominante para o êxito acadêmico em detrimento das evidentes necessidades sociais de relacionamento que, cada vez mais, exigem aprendizagens práticas e vivenciais, articuladas com os conteúdos acadêmicos.

Em relação à variável sexo dos alunos não encontramos diferenças significativas na percepção dos professores, apesar de termos encontrado uma tendência de eles verem os meninos um pouco pior que as meninas nas escalas DE e DT. Contudo, surpreendemo-nos ao observar que as meninas apresentaram escores mais altos que os meninos na escala DE. SchoenFerreira (2001), em seu estudo com adolescentes sobre a construção de identidade, encontrou que não havia diferenças entre os dois gêneros, ao contrário do que havia encontrado na literatura, ou seja, os meninos com mais problemas de comportamento, e considerou que as idéias igualitárias entre os sexos estão cada vez mais presentes nos comportamentos tanto das meninas como dos meninos.

\section{Considerações finais}

Estamos cientes das limitações deste estudo, contudo ele nos mostrou que o efeito do treinamento de professores foi positivo. A percepção dos professores sobre os alunos evoluiu positivamente entre antes e depois do treino para o desenvolvimento de habilidades sociais em sala de aula. A percepção dos alunos sobre si mesmos teve a mesma evolução que a encontrada na percepção dos professores, com exceção para a $8^{\mathrm{a}}$ série, cujo escore em DE, depois do treinamento, situou seus alunos na faixa Clínica. Embora tenhamos encontrado discordâncias entre as percepções de professores e alunos nos dois momentos em que responderam os inventários (pré e póstreinamento), observamos uma evolução na concordância entre eles em todas as escalas, especialmente para a escala DI. 
Vale ressaltar que consideramos os inventários TRF e YSR como excelentes instrumentos de rastreamento e avaliação de problemas de comportamentos dos alunos, que oferecem indicadores (mensuráveis) de ação/intervenção tanto para professores como para pesquisadores.

\section{Referências bibliográficas}

ACHENBACH, Thomas M. (1991). Integrative Guide for the 1991 CBCL/4-18, YSR, and TRF profiles. Burlington, VT: University of Vermont Department of Psychiatry.

AZNAR-FARIAS, Maria (2003). Prevenção de comportamentos antisociais e violentos. Comunicação apresentada no Primeiro Simpósio Internacional da Iniciativa Privada para a Prevenção da Criminalidade, São Paulo. Anais.

BOLSONI-SILVA, Alessandra Turini; MARTURANO, Edna Maria (2002). Práticas educativas e problemas de comportamento: Uma análise à luz das habilidades sociais. Estudos de Psicologia (Natal), 7; p. 227-235.

BORGES, Dâmaris Simon Camelo; MATURANO, Edna Maria (2003). Desenvolvendo habilidades de solução de problemas interpessoais no ensino fundamental. Paidéia, 12, p. 185-193.

CASTRO, Edmilson de (2004). A produção do registro do educador: decifrando sinais. Disponível em: <http://www.espacopedagogico.com.br/ edicoes/8/artigo2241-1.asp?o=r>. Acesso em: 11 ago. 2008.

DEL PRETTE, Almir; DEL PRETTE, Zilda Aparecida Pereira (2001). Psicologia das Relações Interpessoais: vivencias para o trabalho em grupo. 2. ed. Petrópolis: Vozes;

(Org.) (2003). Habilidades Sociais, Desenvolvimento e Aprendizagem. SP, Campinas: Alínea.

DEL PRETTE, Zilda Aparecida Pereira; DEL PRETTE, Almir; GARCIA, Fabíola Alvares et al (1998). Habilidades Sociais do Professor em Sala de Aula: Um Estudo de Caso. Psicol. Reflex. Crit; Porto Alegre, vol. 11 (3); p. 591-603.

FALCONE, Eliane. A evolução das habilidades sociais e o comportamento empático. In: SILVARES, Edwiges Ferreira de Mattos (2000). Estudos de 
casos em psicologia clínica comportamental. v. I. Campinas: Papirus, p. 49-77.

GOTZENS, Concepción (2003). A Disciplina Escolar. Porto Alegre: Artmed.

HARGREAVES Andy; EARL Lorna; RYAN Jim (2001). Educação para mudança: recriando a escola para adolescentes. Porto Alegre: Artmed.

JAMES, Anthony; JAVALOYES, Auxi (2001). Transtornos psicosociales y psicopatologia en la adolescencia. In: Carmina Saldaña. Detección y Prevención en el Aula de los Problemas del Adolescente. Colección Psicología. Madrid, Espanha: Ediciones Pirámide. p. 161-177

MASSOLA, Gustavo Martineli; SILVARES, Edwiges Ferreira de Mattos (1997). Percepção do comportamento infantil por professores versus sexo e encaminhamento para atendimento psicoterapêutico. Psicologia: Teoria e Pesquisa, Brasília, v. 13, n. 3, p. 303-309.

MELO, Márcia Helena da Silva (2004). Crianças com Dificuldade de Interação no Ambiente Escolar: uma intervenção multifocal [Tese de doutorado]. Instituto de Psicologia da Universidade de São Paulo, São Paulo, 2004.

MURTA, Sheila Giardini (2005). Aplicações do Treinamento em Habilidades Sociais: Análise da Produção Nacional. Psic. Reflexão e Crítica, v. 18 (2), p.283-291.

SCHOEN-FERREIRA, Teresa Helena (2001). A Formação da Identidade em Adolescentes: um estudo exploratório com estudantes do ensino médio [Dissertação]. Universidade Federal de São Paulo (UNIFESP), São Paulo, 2001.

TRIANES Torres, Maria Victoria; DE LA MORENA Fernández, Maria Luisa; MUÑOZ Sánchez, Ángela Maria (1999). Relaciones Sociales y Prevención de la Inadaptación Social y Escolar. Málaga, Espanha: Ediciones Aljibe.

; MUÑOZ Sánchez, Ángela Maria (1994). Programa de Educación Social y Afectiva. Málaga, Espanha: Junta de Andalucia.

; JIMÉNEZ, M. (1997). Competencia social: su educación y tratamiento. Madri, Espanha: Pirâmide. 
VILA, Edna Manfredin (2005). Treinamento de Habilidades Sociais em grupo com professores de crianças com dificuldades de aprendizagem: uma análise sobre os procedimentos e efeitos da intervenção. [Dissertação de Mestrado]. UFSCar, São Carlos, 2005.

ZAGURY, Tânia (2006). O Professor Refém. Rio de Janeiro: Record.

\section{AUTORAS}

\section{Dalva ALVES Silva}

Pedagoga, Psicopedagoga e Mestre em Ciências Aplicadas à Pediatria pela Universidade Federal de São Paulo. Técnica em Assuntos Educacionais da Coordenadoria de Assuntos Estudantis/PROGRAD/UNIFESP/Campus São Paulo.

E-mail: dalva.alves@unifesp.br

\section{Maria AZNAR-FARIAS}

Doutora em Psicologia pela Universidade de São Paulo; é professor adjunto aposentado pela Universidade Federal de São Paulo e Coordenadora do Núcleo de Estudos e Pesquisa do Curso de Psicologia da Universidade Católica de Santos.

E-mail: maznar@unisantos.br

\section{Edwiges Ferreira de Mattos SILVARES}

Doutora em Psicologia pela Universidade de São Paulo (USP), professora titular, vice-diretora do Departamento de Psicologia Clínica do Instituto de Psicologia da USP e bolsista do CNPq.

E-mail: efdmsilv@usp.br

Endereço para correspondência:

Rua Pedro de Toledo, 650 - Vila Clementino, São Paulo/SP/BRASIL. 
Recebido em julho de 2008, aprovado em agosto de 2008.

\section{Como citar este artigo:}

ALVES Silva, Dalva; AZNAR-FARIAS, Maria da e SILVARES, Edwiges Ferreira de Mattos. Influência do Treino em Habilidades Sociais na relação professor-aluno: uma contribuição psicopedagógica para professores. Revista ACOALFAplp: Acolhendo a Alfabetização nos Países de Língua portuguesa, São Paulo, ano 3, n. 5, 2008. Disponível em: <http://www.acoalfaplp.net>. Publicado em: setembro 2008. 